\title{
Intervention Effects of Rural Development Programme on Landscape Management in Bulgaria
}

\author{
RADEV Teodor ${ }^{1}$, BORISOV Petar ${ }^{2}$, SOFRONIA Miladinoski ${ }^{3}$ \\ ${ }^{I}$ Agricultural University, Plovdiv, (BULGARIA) \\ ${ }^{2}$ Agricultural University, Plovdiv, (BULGARIA) \\ ${ }^{3}$ Faculty of Tourism and Hospitality, Ohrid, (MACEDONIA) \\ Emails:radev1974@abv.bg,peterborisov@gmail.com,sofmil@yahoo.com
}

\begin{abstract}
This paper aims to make an evaluation of CAP contribution to landscape management in Bulgarian economy of rural areas. To sum up, landscape is a non-commodity output produced as direct or indirect outcome of the activities operating in a particular area and it is valued by society for its functions (use and non use values, ecological, recreational, cultural etc). Due to this complex nature, it produces second-order effects that are captured by the stakeholders in rural areas (farmers or others), and that generate potential markets for new activities.

Therefore, through the generation of these effects, landscape contributes to boosting the economy of rural areas and is an important driver for the whole regional economy.

The Rural Development Programmes of the current period (2007-2013) support measures that can have an added value for this new perspective of the policy. Some of them such as the agri-environmental payments and the measures designed for less favoured areas can have direct and indirect effects in the provision of landscape and in delivering landscape as environmental public good, playing also an important role in terms of financial allocation in the current Rural Development Programme.

The analysis of existing specific measures targeted at local level connected to the landscape allow to distinguish supporting potential landscape-related activities and its role at the economy of rural areas.
\end{abstract}

Keywords: rural development, landscape managemet, Bulgria

JEL: N50

UDK: 338.48-44(497.2-22)

502.131.1:338.483.11(21)

\section{Concepts and Theories}

The concepts of multifunctionality of landscape and of its multiple values represent the starting point of the analysis, to explain the potential generation of socio-economic benefits.

The analysis of the different functions of landscapes and the recognition of their attributes and peculiarities is an essential condition for valuating the possible socio-economic benefits that landscapes may generate in rural areas. The interaction between the fundamental features of landscape, such as its historical, cultural, recreational, production, aesthetic, biodiversity and ecological functions, determines the multifunctional character of landscapes and generates their value as perceived by society. In turn, this potential of satisfying social expectations and needs can represent a valuable factor for generating economic benefits in rural areas. 
To sum up, landscape is a non-commodity output produced as direct or indirect outcome of the activities operating in a particular area and it is valued by society for its functions (use and non use values, ecological, recreational, cultural etc). Due to this complex nature, it produces second-order effects that are captured by the stakeholders in rural areas (farmers or others), and that generate potential markets for new activities. Therefore, through the generation of these effects, landscape contributes to boosting the economy of rural areas and is an important driver for the whole regional economy.

As it is shown by the analysis of examples and studies examined, the potential for local development can be interpreted as direct and indirect benefits for the agricultural sector in particular, and also for the whole regional economy. On the one hand direct socio-economic benefits can arise in terms of job and income opportunity both for farmers and for rural stakeholders other than farmers, from their involvement in activities related to the management, the maintenance and the conservation of specific landscape elements. On the other hand, indirect socio-economic benefits in the regional economy are provided by landscape amenities and by means of all potential activities and opportunities for the local economy directly linked to landscape functions. This sort of indirect benefits may be translated in the development of tourism and recreational opportunities in rural areas. In other hand create in new market opportunity for local products and in the continuation and viability of rural crafts and traditional skills. Additionally, it influences in the inward migration of workers and population growth in specific areas, in the attraction of inward investments. At the end we can summarize and more in general, these benefits can lead to employment creation and maintenance, to positive income effects on the wider rural economy and to the strengthening of cultural heritage, identity and social inclusion.

On this basis, two kinds of interventions can be identified:

- Support to the agricultural sector for actions directly or indirectly beneficial to landscape and aimed at securing a level of provision in line with society's demand (e.g., encourage certain traditional farming practises or method of production particularly beneficial to landscape, avoid land abandonment, convert intensive farming systems into more extensive ones, restore and maintain hedges, rural pathways, terrace fields etc);

- aids to farmers or other local actors to cover initial costs that new activities may imply and to search for new commodity and non commodity markets, in which they may have a competitive advantage (e.g., diversification of on-farm activities and new off-farm activities such as agro-tourism, craft, care and leisure activities, direct selling and marketing of high-value products, etc.)

\section{Methodology}

Indeed, the value of landscape and its multifunctional attributes have been widely acknowledged and studied in the literature, and some definitions of landscape constitute an attempt to explain this concept [1], [2].

The relationship between landscapes and the economy of rural areas suggests that the valorisation and conservation of landscapes has to be supported not only for its inherent value and its nature of environmental public good, but also for its potential to generate socioeconomic benefits in rural areas. Public intervention can therefore target landscapes as important drivers for the economic development of these areas.

The first necessary condition to translate such potential benefits into real opportunities for the actors operating in rural areas is that the characteristics and the state of landscapes in a given area correspond to the ones desired by society. This means that the current level of provision 
of landscapes has to match the societal demand of landscape, and public intervention is required to reverse the "undersupply" of landscape detected in certain areas [3].

The second condition to generate such potential spill-over effects is that the actors operating in rural areas are able to exploit the potential market opportunities offered by landscapes and their functions. Only in this case are the potential benefits likely to be translated into new opportunities for income and jobs.

The reference to these two conditions is important to understand which kind of public intervention is needed, in which circumstances, to generate such landscape-related opportunities.

(1) First condition: public support is required to secure a level of landscape provision in line with society's demand, and therefore in the case of landscape degradation to secure and restore its environmental attributes.

To satisfy this objective, intervention can take the form of support to the agricultural sector for actions directly or indirectly beneficial to landscape. Farmers can, for example, be encouraged to convert intensive farming systems into more extensive ones, and incentives may be provided to encourage certain traditional farming practises or methods of production particularly beneficial for landscape or to maintain sufficient levels of production in areas where land abandonment is a factor of landscape degradation.

Public support can also be provided to other actors operating in rural areas, such as local contractors or associations, to undertake actions and specific works directly aimed at the maintenance and restoration of landscape features (e.g., hedges and tree rows, rural pathways, farm roads, dry stone walls, terraced fields, etc.), whose existence is not related to the production of agricultural commodity outputs.

(2) Second condition: the intervention should be targeted to the farmers and the local economy in view of allowing them to best capture the opportunities offered by landscape amenities and functions. Not all farmers, for example, are able to diversify on-farm activities, or to engage in new off-farm activities (agri-tourism, craft, care and leisure activities, production of added value products, direct selling and marketing of high-value products and investments in higher value chains), or to cooperate with other sectors of the rural economy (e.g., agro-industry, tourist industries, local networks with public and private partnerships etc.). Financial support can therefore help farmers or other local actors to cover initial costs that new activities may imply and to search for new commodity and non commodity markets in which they may have a competitive advantage.

The Rural Development Programmes of the current period (2007-2013) support measures that can have an added value for this new perspective of the policy. Some of them such as the agri-environmental payments and the measures designed for less favoured areas can have direct and indirect effects in the provision of landscape and in delivering landscape as environmental public good, playing also an important role in terms of financial allocation in the current Rural Development Programmes. On the other hand the measures designed to add value to agricultural products, to provide basic services for the economy and rural population, to promote village renewal and development, and to support tourism activities seem to be appropriate to support farmers and the local economy to best capture the opportunities offered by landscape amenities and functions. The existence of specific measures targeted at local level to capture the landscape site specificity and to boost the economy of such areas by supporting potential landscape-related activities is very important to help understanding and promoting the link between landscape and the economy of rural areas.

The analysis of the different functions of landscapes and the recognition of their attributes and peculiarities is an essential condition for valuating the possible socio-economic benefits that landscapes may generate in rural areas. In this respect, this chapter provides a preliminary overview on these aspects, based on literature research. 


\section{Results}

Based on the above, it is possible to analyse the extent to which the Rural Development Policy 2007-2013 and its set of measures may support those types of actions as previously identified. Among the 44 measures proposed to Member States by Council Regulation (EC) n. $1698 / 2005$, it is possible to identify a set of 20 measures related, to a different extent and in different ways, to landscapes. As shown in Table 1 below, this set of 20 measures can be further broken down into two big groups according to the two conditions mentioned above:

(1) the first group of measures is related to the "provision of landscapes";

(2) the second group concerns the provision of "landscapes related services and activities", i.e., actions helping rural stakeholders to carry out activities that are potentially linked to the existence and attractiveness of landscapes in rural areas. The measures of EAFRD are codified as follows ${ }^{1}$ :

Table 1. Main Rural Development measures supporting directly or indirectly the provision of landscapes and helping the creation of landscape-related activities

\begin{tabular}{|c|c|c|c|c|}
\hline \multirow[b]{2}{*}{ Code } & \multirow[b]{2}{*}{ Type of measure } & \multicolumn{2}{|c|}{$\begin{array}{l}\text { Provision of } \\
\text { landscape }\end{array}$} & \multirow{2}{*}{$\begin{array}{l}\text { Landscapes related } \\
\text { services and activities }\end{array}$} \\
\hline & & Direct & Indirect & \\
\hline & AXIS 1 & & & \\
\hline 111 & $\begin{array}{l}\text { Vocational training, information actions, including } \\
\text { diffusion of scientific knowledge and innovative } \\
\text { practices in the agricultural }\end{array}$ & & & \\
\hline 114 & Use by farmers and forest holders of advisory services & & & \\
\hline 115 & $\begin{array}{l}\text { Setting up farm management, farm relief and farm } \\
\text { advisory services, as well as forestry advisory services }\end{array}$ & & & \\
\hline 121 & Farm modernisation & & & \\
\hline 123 & Adding value to agricultural and forestry products & & & \\
\hline 132 & $\begin{array}{l}\text { Supporting farmers who participate in food quality } \\
\text { schemes }\end{array}$ & & & \\
\hline \multirow[t]{2}{*}{133} & $\begin{array}{l}\text { Supporting producer groups for information and } \\
\text { promotion activities for products under food quality } \\
\text { schemes }\end{array}$ & & & \\
\hline & AXIS 2 & & & \\
\hline 211 & Natural handicap payments to farmers in mountain areas & & & \\
\hline 212 & $\begin{array}{l}\text { Payments to farmers in areas with handicaps, other than } \\
\text { mountain areas }\end{array}$ & & & \\
\hline 213 & $\begin{array}{l}\text { Natura } 2000 \text { payments and payments linked to Directive } \\
2000 / 60 / \mathrm{EC}\end{array}$ & & & \\
\hline 214 & Agri-environmental payments & & & \\
\hline \multirow[t]{2}{*}{216} & Support for non-productive investments & & & \\
\hline & AXIS 3 & & & \\
\hline 311 & Diversification into non-agricultural activities & & & \\
\hline 313 & Encouragement of tourism activities & & & \\
\hline 321 & Basic services for the economy and rural population & & & \\
\hline 322 & Village renewal and development & & & \\
\hline 323 & Conservation and upgrading of the rural heritage & & & \\
\hline \multirow[t]{2}{*}{331} & $\begin{array}{l}\text { Training and information for economic actors operating } \\
\text { in the field covered by Axis } 3\end{array}$ & & & \\
\hline & LEADER AXIS & & & \\
\hline 412 & $\begin{array}{l}\text { Local development strategies. Environment/land } \\
\text { management. }\end{array}$ & & & \\
\hline 413 & $\begin{array}{l}\text { Local development strategies. Quality of } \\
\text { life/diversification. }\end{array}$ & & & \\
\hline
\end{tabular}

Source: Landscape and rural areas: towards an economic valuation of socio-economic impacts

\footnotetext{
${ }^{1}$ Commission Regulation (EC) No 1974/2006 of 15 December 2006 laying down detailed rules for the application of Council Regulation (EC) No 1698/2005 on support for rural development by the European Agricultural Fund for Rural Development (EAFRD).
} 


\section{Measures Related to the Provision of Landscapes}

An additional classification is possible for the measures identified as potentially related to the provision of landscapes. Firstly, 2 measures of Axis 2, Agri-environmental payments and Support for non-productive investments (measures 214 and 216 respectively) have a direct relationship with landscape provision. Their objectives, as defined in the legal framework of the rural development policy, refer in fact directly to the protection and improvement of landscapes and their features, thus potentially covering actions and commitments aimed at their delivery, such as:

a) upkeep of landscapes and maintenance of high nature-value farmland areas, including the conservation of historical features (e.g. stonewalls, terraces, small wood);

b) management and conversion of pastures;

c) extensification of farming systems that are directly related to high landscape quality and diversity.

A second group of measures, mainly from Axis 2, indirectly relates to the provision of landscapes, by improving the sustainability of agriculture and natural capital. These measures include compensatory payments for Less Favoured Areas (LFA) (measures 211 and 212), the main aim of which is to avoid land abandonment and its negative effects on landscape and the countryside, and the measures linked to Natura 2000 payments and payments linked to Directive 2000/60/EC (Water Framework Directive) (measure 213). Some measures of Axis 1 give support to farmers who make use of advisory services to improve their scientific knowledge and education on farming techniques and sustainable use of natural resources, including the maintenance and enhancement of landscapes (measures 111, 114, and 115).

Other measures of Axis 3, which can also indirectly influence the provision of landscapes, are the ones conceived for specific actions (e.g. studies, investments) associated with the maintenance, restoration and upgrading of the natural and cultural heritage, or aimed at increasing the economic attractiveness of villages or group of villages (measure 323). Finally, the Axis 4 measure concerning local strategies by Local Action Groups on the environment and land management (measure No 412) can also indirectly affect the provision of landscapes.

\section{Measures Related to "Landscape Related Services and Activities"}

Some measures of Axes 1 and 3 refer to different types of actions aimed at enhancing the economic viability of rural areas through diversification of agricultural activities and thus help farmers to capture the opportunities offered by landscape amenities and functions:

- measures 311 and 313 support farmers to undertake non-agricultural activities: service and craft activities (bed and breakfast, education and social activities on farm, production of local products), trade activities (creation of local store attached to the farm and direct selling of self-made products), and infrastructure for tourist sites and recreational activities.

- measures 121, 123 and 132 respectively help farmers to bear the costs for investments in the holding, support the processing and marketing of existing and new products and encourage the participation in food quality schemes.

- measure 321 provides support to cover the setting up of basic services for the rural population, including cultural and leisure activities and related small-scale infrastructure for the economy of rural areas (leisure, sport and cultural activities, child care facilities, transport services, telecommunication services).

- measures 322 and 413 give support to actions aimed at village renewal and development in order to face depopulation and economic decline of certain areas and to the 
implementation of local development strategies focused on quality of life and diversification.

Table 2. Payments of the measures related to landscape

\begin{tabular}{|c|c|c|c|c|c|c|}
\hline \multirow[b]{2}{*}{ Measure } & \multicolumn{2}{|c|}{ Applications filed } & \multicolumn{2}{|c|}{ Approved applications } & \multicolumn{2}{|c|}{ Payments } \\
\hline & $\begin{array}{l}\text { number } \\
\text { proposed } \\
\text { projects }\end{array}$ & $\begin{array}{c}\text { Expenditures } \\
\text { BGN }\end{array}$ & $\begin{array}{l}\text { number } \\
\text { selected } \\
\text { projects }\end{array}$ & $\begin{array}{c}\text { Expenditures } \\
\text { BGN }\end{array}$ & $\begin{array}{c}\text { number } \\
\text { ended } \\
\text { projects }\end{array}$ & $\begin{array}{c}\text { Expenditures } \\
\text { BGN }\end{array}$ \\
\hline \multicolumn{7}{|c|}{ Indirect provision of landscape } \\
\hline 111 & 169 & $55,814,779$ & 107 & $29,360,494$ & 30 & $1,804,619$ \\
\hline 114 & 58 & 142,094 & 0 & 0 & 0 & 0 \\
\hline \multicolumn{7}{|l|}{115} \\
\hline 211 & 131,284 & & 129,527 & $151,760,164$ & 129,527 & $142,649,397$ \\
\hline 212 & 53,373 & & 52,725 & $45,438,110$ & 52,725 & $43,493,036$ \\
\hline 213 & 2,427 & & 0 & 0 & 0 & 0 \\
\hline \multicolumn{7}{|l|}{323} \\
\hline \multicolumn{7}{|l|}{412} \\
\hline $\begin{array}{l}\text { Total Indirect } \\
\text { Provision }\end{array}$ & 187,311 & $55,956,873$ & 182,359 & $226,558,768$ & 182,282 & $187,947,052$ \\
\hline \multicolumn{7}{|c|}{ Direct provision of landscape } \\
\hline 214 & 6,662 & & 5,127 & $37,777,167$ & 5,127 & $36,255,434$ \\
\hline \multicolumn{7}{|l|}{216} \\
\hline $\begin{array}{l}\text { Total Direct } \\
\text { Provision }\end{array}$ & 6,662 & & 5,127 & $37,777,167$ & 5,127 & $36,255,434$ \\
\hline \multicolumn{7}{|c|}{ Landscape related services and activities } \\
\hline 121 & 3,501 & $982,006,199$ & 2,609 & $664,156,937$ & 1,882 & $464,855,162$ \\
\hline 123 & 495 & $521,113,196$ & 358 & $343,316,194$ & 124 & $71,532,660$ \\
\hline \multicolumn{7}{|l|}{132} \\
\hline \multicolumn{7}{|l|}{133} \\
\hline 311 & 428 & $144,542,501$ & 197 & $67,499,737$ & 66 & $11,663,016$ \\
\hline 313 & 111 & $39,243,024$ & 32 & $7,839,154$ & 27 & $3,700,731$ \\
\hline 321 & 753 & $2,681,900,556$ & 226 & $723,458,503$ & 213 & $340,772,960$ \\
\hline 322 & 522 & $585,960,008$ & 269 & $283,122,655$ & 225 & $126,628,089$ \\
\hline \multicolumn{7}{|l|}{331} \\
\hline \multicolumn{7}{|l|}{413} \\
\hline $\begin{array}{l}\text { Total related } \\
\text { services and } \\
\text { activities }\end{array}$ & 5,810 & $4,954,765,484$ & 3,691 & $2,089,393,180$ & 2,537 & $1,019,152,618$ \\
\hline TOTAL & 199,783 & $5,010,722,357$ & 191,177 & $2,353,729,115$ & 189,946 & $1,243,355,104$ \\
\hline
\end{tabular}

\section{Importance of the Measures Related to Landscape in the Rural Development Programmes for the Period 2007-2013}

According to the classification provided in the previous chapters, chart 1 gives a picture of the importance of the three groups of landscape-related measures in terms of the allocated expenditures in the Rural Development Programmes of the 2007-2013 programming period in the Bulgaria. 


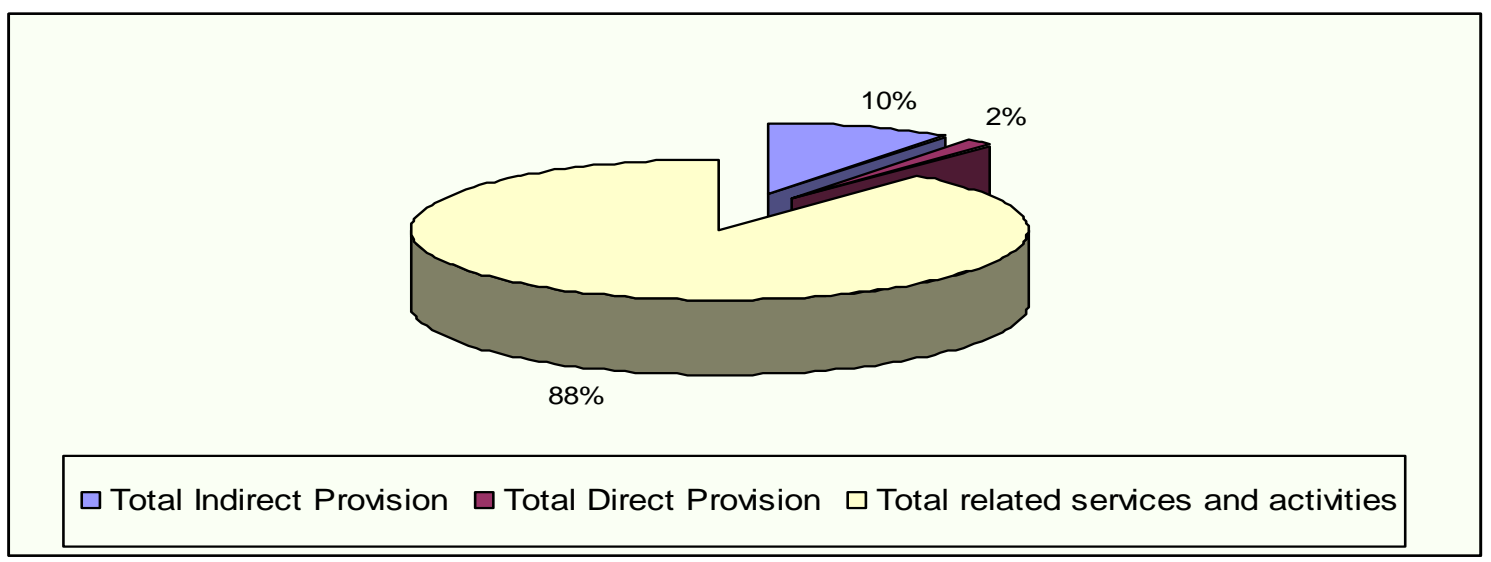

Chart 1. Importance of potentially landscape-related group of measures, in terms of total allocated expenditure (including EAFRD contribution and national co-funding) for the 2007-2013 programming period, in the Bulgaria ${ }^{2}$ Source: own elaboration

The chart below provides a more detailed overview, by single measure, of the financial weight of the rural development measures identified in the previous chart, with respect to the overall financial envelope for national rural development programme.

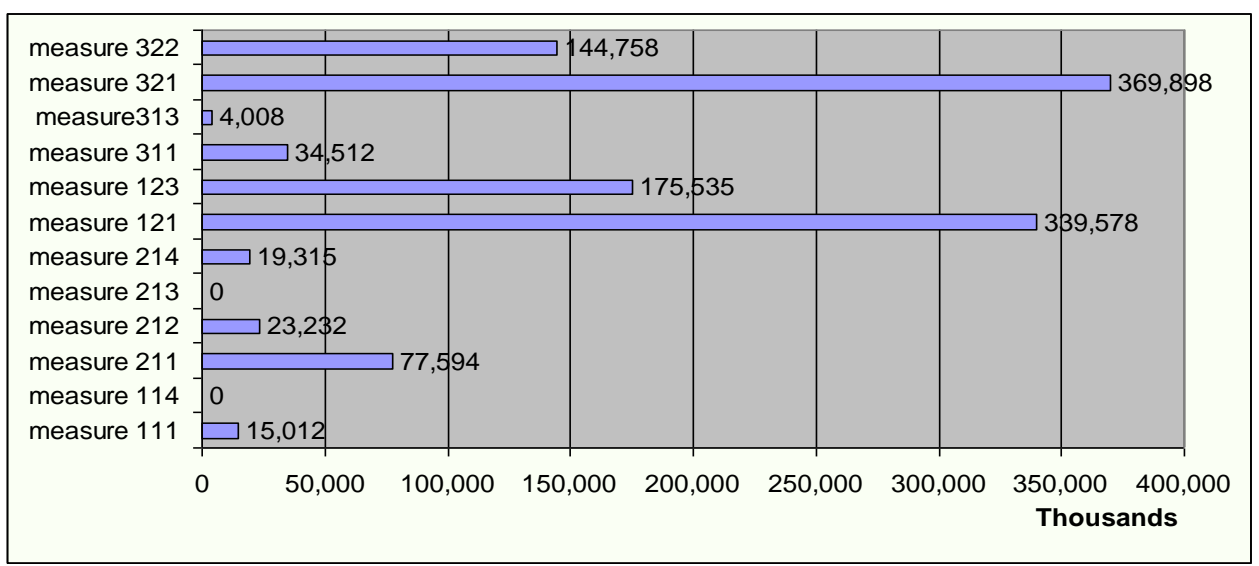

Chart 2. Total expenditures by measures /thousands of euro/ Source: [4]

Measure 321 and measure 121 are the most favourable among Bulgarian beneficients.

Expenditures on these measures exceeded the followings in several times. As reasons can be pointed the low level of modernization of holdings and not well-provided rural areas with infrastructure so there is a necessity of big investments in these directions. Other measures 114 and 213 don't report any cost because of rejection of all proposed projects.

\footnotetext{
${ }^{2}$ Information on Financial plans per Member State, programming period 2007-2013 in Statistical and Economic Information Report 2009.
} 


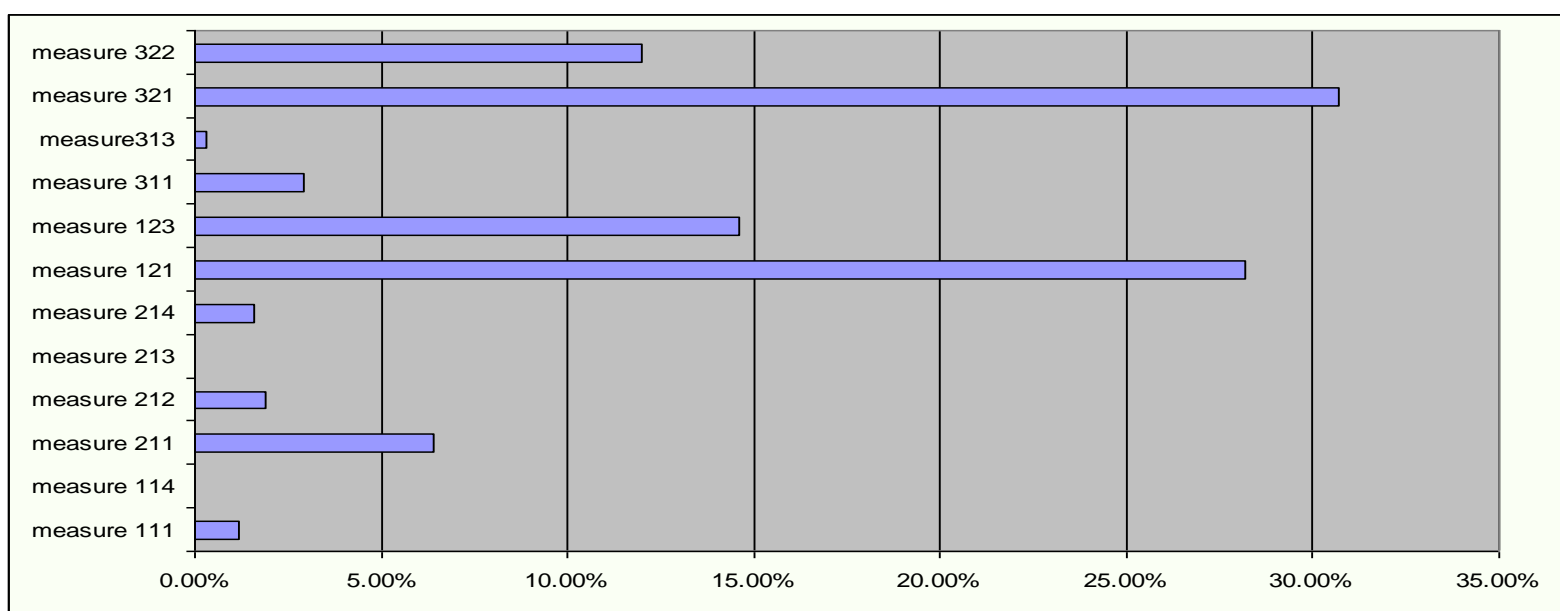

Chart 3. Relative importance of potentially single landscape-related measures, in terms of total allocated expenditure (including EAFRD contribution and national co-funding) for the 2007-2013 programming period, in Bulgaria

Source: own elaboration based on the financial plan - programming period 2007-2013

Measures 321 and 121 account for more than $50 \%$ of the budget allocated across all the rural development programmes. Basic services for the economy and rural population (measure 321) cover, alone, some $30 \%$ of the total allocation.

Concerning in particular the "measures directly related to the provision of landscape", the Agri-environmental (measure 214) is applied only. Measure 214 accounts for the majority of RDP funding in several other northern Member state (FI, DK, AT, IE) allocate between 30\% and $50 \%$ of their rural development funds to this measure.

The significance of this chart and figures for assessing the contribution of rural development programmes to the direct provision of landscapes has however to be taken with caution since measure 214 covers a wide range of environmental objectives, not necessarily in connection with the provision of landscapes.

Table 3. Actions delivering "agrarian landscape" under the Agri-Environment Measure (214)

\begin{tabular}{|l|c|}
\hline \multicolumn{1}{|c|}{ Actions } & Adopted proposals \\
\hline Organic farming & 377 \\
\hline Organic bee keeping & 155 \\
\hline Maintain pastures & 598 \\
\hline Maintain habitats of protected birds & 1 \\
\hline Maintain and manage traditional orchards & 12 \\
\hline Introduction of rotation to protect soil and water & 36 \\
\hline Control of soil erosion & 312 \\
\hline Use of local, rare breeds of livestock & 182 \\
\hline Maintain or introduce extensive grazing practices & \\
\hline
\end{tabular}

Source: http://prsr.government.bg/

Concerning the measures identified as "indirectly related to landscape", the most important, in terms of budget allocation, are the measures targeted to Less Favoured Areas which cover payments to farmers in areas with handicaps in mountain areas (measure 211) and in other areas (measure 212) and which respectively account for $67 \%$ and $20,1 \%$ of the total "indirect" measures. These two measures are particularly important for the conservation and preservation of landscape in the areas concerned. The first objective of these measures is in fact to avoid land abandonment, which can have negative consequences for the countryside as a whole and also for landscapes. 


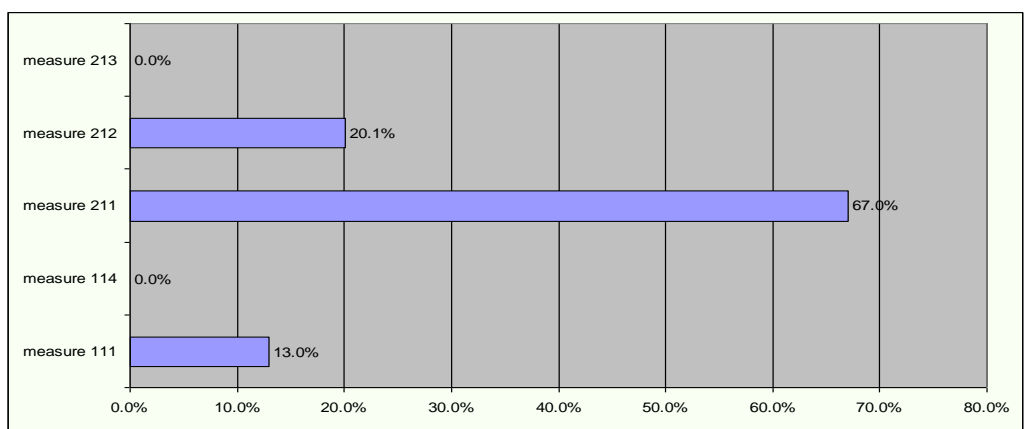

Chart 4. Proportion of total public rural development expenditure for the measures indirectly related to landscape, in Bulgaria

Source: own elaboration

Table 3 below is based on the results of the Evaluation of RDP in Bulgaria and shows an increasing interest to the measures in the last two years. These results do not give any information on the importance of these actions in terms of public expenditure within the programmes, only the amount of expenditures is reported.

It is reported increasing interests to these measures during the last year. Expenditures at year base raise as well the number of selected proposals. Rural Development Programmes contribute landscape in mountain areas better then other areas.

Table 4. Number of submitted and selected proposals on M 211 and M 212 by years

\begin{tabular}{|l|r|r|r|r|r|r|}
\hline \multirow{2}{*}{ year } & \multicolumn{3}{|c|}{ Measure 211 } & \multicolumn{3}{c|}{ Measure 212 } \\
\cline { 2 - 7 } & $\begin{array}{c}\text { Submitted } \\
\text { proposals }\end{array}$ & $\begin{array}{c}\text { Selected } \\
\text { proposals }\end{array}$ & $\begin{array}{c}\text { Expenditures } \\
(000 \text { euro })\end{array}$ & $\begin{array}{c}\text { Submitted } \\
\text { proposals }\end{array}$ & $\begin{array}{c}\text { Selected } \\
\text { proposals }\end{array}$ & $\begin{array}{c}\text { Expenditures } \\
(000 \text { euro })\end{array}$ \\
\hline 2007 & 22.649 & 22.646 & 12.377 & 9.417 & 9.411 & 3.786 \\
\hline 2008 & 24.151 & 24.026 & 11.505 & 10.017 & 9.977 & 3.801 \\
\hline 2009 & 26.246 & 26.134 & 18.436 & 10.835 & 10.793 & 4.642 \\
\hline 2010 & 29.031 & 28.308 & 15.522 & 11.619 & 11.301 & 4.234 \\
\hline 2011 & 29.210 & 28.265 & 19.403 & 11.489 & 11.194 & 6.719 \\
\hline Total & $\mathbf{1 3 1 . 2 8 7}$ & $\mathbf{1 2 9 . 3 7 9}$ & $\mathbf{7 7 . 2 4 3}$ & $\mathbf{5 3 . 3 7 7}$ & $\mathbf{5 2 . 6 7 6}$ & $\mathbf{2 3 . 1 8 2}$ \\
\hline
\end{tabular}

Concerning the group of measures potentially supporting landscape-related activities and services, the most important in terms of total public expenditure allocated is the Axis 3 measure 321 "Basic services for the economy and rural population" and the Axis 1 measure 121 "Modernisation of agricultural holdings". They account for $66 \%$ of the total budget. No relevant actions under this measure have been found by means of the screening exercise, in the Rural Development Programmes as delivering agrarian landscapes.

Finally, the measure 123 "Adding value to agriculture and forestry products" absorbs over $16 \%$ of the budget. However as for the measures 321 and 121 no relevant actions targeted at delivering agrarian landscapes have been found under this measure. All the other measures are of minor importance, each of them absorbing less than $4 \%$ of the total public expenditure of all Rural Development Programmes. Overall, the relative importance of these measures can vary significantly (chart 5). 


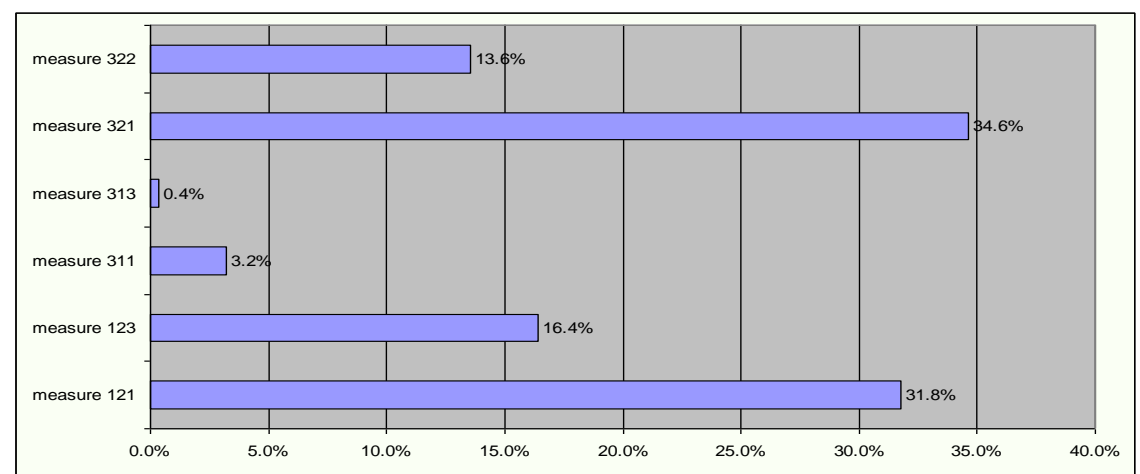

Chart 5. Proportion of total public rural development expenditure for the measures related to the socio-economic effects of landscape, in Bulgaria Source: own elaboration

Finally, the most common actions found in the Rural Development Programmes as delivering agrarian landscape under the 321 measure are displayed in Table 5.

This measure provides support to cover the setting up of basic services for the rural population - maintenance and constructing of water supply networks and sewerages. Other activities as cultural, social and leisure activities are also objecting on investments. Roads contribute for boosting the economy of rural areas and also improve the landscape. All expenditures in these activities make the landscape more attractive for people.

Table 1. Actions to provide agrarian landscape in the Rural Development Programmes for 321 /09.02.2012/

\begin{tabular}{|c|c|c|c|}
\hline Roads - new (кт) & Roads - new (euro) & Roads - existing (кт) & Roads - existing (euro) \\
\hline 18.07 & 3544832.05 & 414,76 & 76812620.35 \\
\hline $\begin{array}{l}\text { Water supply network } \\
\text { - new (кm) } \\
\end{array}$ & $\begin{array}{c}\text { Water supply network - } \\
\text { new (euro) }\end{array}$ & $\begin{array}{c}\text { Water supply network - } \\
\text { existing (км.) } \\
\end{array}$ & $\begin{array}{c}\text { Water supply network - } \\
\text { existing (евро) }\end{array}$ \\
\hline 160,19 & 26605221.57 & 1047,75 & 146628277.20 \\
\hline $\begin{array}{c}\text { Sewerage and } \\
\text { purifying - new (кm) }\end{array}$ & $\begin{array}{l}\text { Sewerage and purifying - } \\
\text { new (euro) }\end{array}$ & $\begin{array}{c}\text { Sewerage and purifying - } \\
\text { existing ( } \mathrm{km})\end{array}$ & $\begin{array}{l}\text { Sewerage and purifying - } \\
\text { existing (euro) }\end{array}$ \\
\hline 655,14 & 96290470.64 & 75,34 & 17943867.27 \\
\hline $\begin{array}{l}\text { Centres of culture - } \\
\text { new (n.) }\end{array}$ & $\begin{array}{c}\text { Centres of culture - new } \\
\text { (euro) }\end{array}$ & $\begin{array}{l}\text { Centres of culture - } \\
\text { existing (n.) }\end{array}$ & $\begin{array}{l}\text { Centres of culture - existing } \\
\text { (euro) }\end{array}$ \\
\hline 6 & 3312557.97 & 46 & 11357358.92 \\
\hline $\begin{array}{l}\text { Sport places - new } \\
\text { (n.) }\end{array}$ & $\begin{array}{l}\text { Sport places - new } \\
\text { (euro) }\end{array}$ & $\begin{array}{c}\text { Sport places - existing } \\
(\mathrm{n} .)\end{array}$ & Sport places - existing (euro) \\
\hline 34 & 20984095.32 & 30 & 15148564.55 \\
\hline $\begin{array}{l}\text { Centres of social } \\
\text { services - new (n.) }\end{array}$ & $\begin{array}{c}\text { Centres of social services - } \\
\text { new (euro) }\end{array}$ & $\begin{array}{c}\text { Centres of social services } \\
\text { - existing (n.) }\end{array}$ & $\begin{array}{c}\text { Centres of social services - } \\
\text { existing (euro) }\end{array}$ \\
\hline 6 & 3503125.96 & 8 & 2251841.95 \\
\hline
\end{tabular}

\section{Conclusions}

The potential for local development is at the core of the justification of public policies in support of the valorization and conservation of landscapes. The first necessary condition identified is that the characteristics and the state of landscapes in a given area correspond to the ones desired by the society. This means that the level of provision of landscapes must match the societal demand. The second condition to generate spill-over effects is that the actors operating in rural areas are able to exploit the potential market opportunities offered by landscapes and their functions. Only in this case are the potential benefits likely to be translated into new opportunities for income and jobs. 
In conclusion the measures are relevant and contribute regional development. In the matter of fact, the adoption of them must be accelerated in order to achieve economic and social benefits in certain areas.

\section{REFERENCES}

1. Vanslembrouck I., Van Huylenbroeck G. (2005). Landscape Amenities: Economic Assessment of Agricultural Landscapes. Springer, ISBN: 1402031343. (No.): 202.

2. Marangon F, Tempesta T, (2008). The economic evaluation of the rural landscape in Italy. Third Workshop on Landscape Economics, May 2008 Versailles (Paris).

3. Cooper, T., Hart K., Baldock D. (2009). The Provision of Public Goods Through Agriculture in the European Union, Report Prepared for DG Agriculture and Rural Development, Contract No 30-CE0233091/00-28, Institute for European Environmental Policy: London. EC,

4. http://prsr.government.bg/

\section{Article history:}

- Received 10 September 2019

- Accepted 01 December 2019 